\title{
'I felt that I do live in the UK now': international students' self-reports of their English language speaking experiences on a pre-sessional programme
}

\begin{abstract}
This article focuses on the English language experiences of a group of pre-sessional students, an underrepresented group in the literature on language and education. In particular, it investigates the opportunities that such students have to use English outside the classroom, shown to be a key factor in student satisfaction with their study abroad experience. Drawing on data from questionnaires, interviews and on-line diaries, we show that students have a variety of opportunities to use English; however, these opportunities may require students to engage in complex negotiations right from the beginning of their sojourn in the UK. Micro-analysis of the data shows that agency is a key construct in understanding students' representations of their English encounters as they begin their lives in the UK. The article concludes with some suggestions as to how pre-sessional courses may develop students' linguistic and socio-cultural skills in order that they interact successfully in English outside the classroom.
\end{abstract}

\section{Introduction}

As has been well-documented, increasing numbers of international students are choosing to study in an English speaking country, particularly Australia, New Zealand, the United States of America, Canada and the United Kingdom. In the UK context, UKCHISA (UK Council for International Student Affairs) reported 251,310 international students from outside the EU registered at UK universities for the academic year 2008/2009, and 117,660 students from EU countries other than the UK. Thus, international students make up a significant proportion of the UK student population, impacting on both the economic and the social contexts of British universities. However, in spite of the obvious importance of international students in the UK, previous research on the international student experience has mainly been carried out in Australia, New Zealand and the USA (Jackson 2008:10).

One of the main reasons international students give for studying in an Englishspeaking country is the opportunity afforded to improve their English language skills. However, opportunities to speak English, especially outside the classroom, are reported as being quite rare and many international students are frustrated and disappointed by this lack of interactional contact, especially in social situations (see for example, Lewthwaite 1996; DuFon and Churchill 2006; Hassell 2006; Brown 2009). 
Many international students begin their lives in UK on a pre-sessional programme. A presessional programme is an intensive English language programme held during the summer to improve the academic language skills of students' whose language test scores are slightly below the requirement for their chosen degree programme. For many international students, the pre-sessional course represents their initial experience of life in the UK . Ward et al. (2001:142), in their discussion of culture shock, argue that:

It is important these sojourners adapt to the new culture rapidly in order that they may operate effectively in whatever they are doing

This may be particularly difficult for students whose first language is not English as they may also suffer from 'language shock' (Leki 1992:11, cited in Chang and Strauss 2010: 4180), that is, a feeling of having inadequate language skills to live in the new country.

Nevertheless, despite the additional pressure bilingual international students may face when they first arrive in country, research in this area is under-represented. Unlike many previous studies, which have tended to rely on survey data, this study, following Morita (2004) and Chang and Strauss (2010), focuses on the students' point of view and gives voice to the experiences of a particular group of bilingual international students who were following a 15-week pre-sessional programme in the UK. This study therefore answers Segalowitz et al.’s call (2004:15, cited in Jackson 2008:10) to:

More fully explore some of the qualitative aspects of learning afforded by a particular context. This means looking at the nature of the communicative interactions available to the learner and actually entered into, taking into account all communicative opportunities.

This research project aimed to respond to two research questions. The first question, aimed at discovering the range and nature of students' language use outside the classroom, was:

1. What opportunities to use English outside the classroom are reported by international students on a pre-sessional English course in the UK?

The second question focused on uncovering the 'nature of the communicative interactions' and asked:

2. How do students represent their encounters outside the classroom?

\section{Background}


Previous studies have identified a series of difficulties that international students at universities in English-speaking countries confront (see, for example, Perrucci and Hu 1995 and Morita 2009). As Cushner and Karim (2004:292) note:

Study abroad students are faced with numerous transitional and adjustment challenges that make them different from their local counterparts. The most salient of these challenges for these students is to make a successful intercultural transition as quickly as possible and still remain focused on their academic mission.

The problems faced by pre-sessional students making the transition to life as a student in a British university are different to those faced by other international students who arrive and start their degree courses immediately. Whilst pre-sessional students do not face the same academic pressures that full-time degree courses involve, neither do they have access to support mechanisms such as induction week, 'buddying' and mentoring schemes. Moreover, opportunities for social contact may be more limited as generally home students are absent during the summer months.

Previous research shows that difficulties faced by international students generally fall into four groups: academic, social (such as contact with local people), cultural (such as understanding and working within cultural norms) and personal (such as financial difficulties) (Wan et al.1992; Perrucci and Hu 1995; Lethwaite 1996; Spencer-Oatey and Xiong 2006; Morita 2009; Cheng and Strauss 2010). A common finding of these studies is that English language proficiency plays a key role in many of these difficulties.

Wan et al. (1992), for example, looked at factors affecting academic stress in a group of international students in the United States. They concluded that:

Students who perceived themselves as having better English-language skills perceived the same academic situations as less stressful than did students who perceived themselves to have weaker language skills. ... English-language skills appeared to override all other concerns, which suggests that international students' perceived language skills have the most significant influences on their appraisal of the stressfulness of classroom situations (ibid.:617)

Yeh and Inose (2003), citing Mori (2000), note that language difficulties seem to be the most significant issue not only in terms of the effect on academic performance but also on social interaction. Morita (2009) in a detailed case study highlights the difficulty a post-graduate student faces when trying to 'gain access to oral practices...not only inside but outside the classroom’ (ibid:456). 
Xu (1991) found that students’ perceptions of their English ability were more important in measuring achievement than measures purported to be more objective, such as scores in IELTS or TOEFL examinations ( for example, Xu 1991). As Chang and Strauss (2010: 423) argue:

[the] psychological feeling of incompetence is probably more debilitating than the actual language ability.

These findings are similar to those of Lewthwaite (1996) in his study of cross-cultural adaptation. Lewthwaite found that international students often felt that their academic English was adequate but that their social English was not. As a result, they tended to avoid social situations. Lewthwaite (ibid) concluded that although the students in his study were integrated into academic life, they were not integrated into the host culture. There are echoes of this in our own data as one student reported his or her greatest disappointment as follows:

\footnotetext{
Extract 1

It is understanding of real conversation. if I am outside my class, I can't understand what native speakers talk together, so sometime I feel to be isolated and to not feel confident to use my English.1
}

\section{Participants and data collection}

The international students in this study were all on a 15-week pre-sessional programme in a British university. A pre-sessional programme represents a rather 'atypical' university context in that it takes place over the summer months and the opportunities students have for integration into university life are inevitably more limited. However, it represents an important period of settling in to academic life, which may have a significant impact on the way in which subsequent experiences are dealt with. What is more, students on pre-sessional courses are, at the same time as adapting to academic life, often learning how to live in the UK, negotiating access to services and developing an understanding of cultural norms. They are, then, under pressure academically, linguistically and socially.

Of the 42 students on the pre-sessional programme in this study, the vast majority were from China (15) or Taiwan (11), with a further 11 from Thailand, two from Japan and one each from Iran, Vietnam and Kazakhstan. Nearly all the students were preparing to study on postgraduate programmes in business. Consent forms were signed by 39 students. Data collection methods used were an on-line questionnaire, an on-line diary and follow-up interviews. The main data collection instruments were administered in the first four weeks of 
the programme in order to uncover students’ English language speaking practices at the early stages of their university lives.

The questionnaire was administered in the second week of the programme and 34 students responded. The aim was to obtain some general information about the students and their situation, their reasons for studying in the UK, their perceptions of the opportunities they had for using English, and their experiences so far.

The students were then asked to keep an on-line diary over a period of 7 days at some time during the third and fourth weeks of their course. In these diaries, they were asked to record any episode, or what we called 'encounter', in which they spoke English outside the classroom. For each entry, they recorded where the encounter took place, who they spoke to, how long they spoke for, what they talked about and how they felt about it. 26 students recorded 161 encounters. The number of encounters per student ranged from one to 17, with the average being just over six per student. Of course, these results are unlikely to give a complete record of all encounters, but they represent a record of encounters that the students themselves saw as significant. The aim of the diaries then was to gain an overview of the nature of the English-speaking encounters that the students took part in and to identify any common themes in their experiences.

Finally, in week eight, eight students volunteered to be interviewed and were asked to talk about their experiences of using English. Each interview lasted around 30 minutes and was audio-recorded with the student's permission.

The data from the questionnaires, diaries and interviews were all coded and then categorised (Miles and Huberman 1994; Richards 2003). While some codes were predetermined, based on our experiences of working with international students and from the literature on study abroad, others emerged as the data were examined. For example, codes such as 'service encounter' and 'social encounter' were decided in advance, but new codes, such as 'academic encounter' were assigned as the data were examined (given that students were asked to describe use of English outside the classroom, it was not anticipated that students would describe activities concerning their studies).

This analysis provided the information required to answer research question one. To answer research question two, a micro-analysis of the diary entries was carried out to identify syntactic choices students made in their representations of their encounters. This enabled us to uncover how the students positioned themselves vis-à-vis their interlocutors. From this analysis the construct of agency (Ahearn 2001; Morita 2004; Chang and Strauss 
2010) emerged as important in understanding the students' perceptions of their role in the success or otherwise of their encounters.

\section{Findings}

When looking at the type and frequency of encounters, the data obtained from the on-line diaries was particularly helpful. The interview data provided more detailed information, particularly concerning to whom the students were talking. In this section, we introduce the kinds of service, social, casual and academic encounters reported by the students, supported by data extracts. We then go on to examine sections of the on-line diary data in detail

\section{Types of Encounter}

\section{Service encounters}

By a service encounter we mean that language is used transactionally to obtain information or to get things done. For example, one student reports on phoning the bank: 'I did not received my pin code and asked them to mail the code again'.

The largest number of encounters recorded, discussed or described were service encounters. In the questionnaire, for example, all but one of the students reported using English at the shops or at the bank, while 88 service encounters were entered in the on-line diaries, which represented just over half of the total number of entries.

The type and location of the service encounters is reasonably predictable, given the moment in which the data were collected (i.e. in the third week of a pre-sessional programme). Encounters at the accommodation office and in banks represented the highest number reported, while students also described encounters in shops, particularly mobile phone shops, restaurants, markets, university offices and concerning travel.

It is noticeable that the students reported in their diaries that service encounters are generally short, with more than half lasting five minutes or less. However, there were 12 service encounters which lasted more than ten minutes. Of these, the majority involved either getting information or signing a contract for a mobile phone, or solving problems with the bank. These longer encounters show that students frequently need to use their English to negotiate quite complex situations very soon after they arrive in the UK.

\section{Social Encounters}


Social encounters are where the language is used interactionally, to start or maintain relationships. In one encounter, for example, a student reported talking to another student from his/her class: 'we cook together, chatted with each other'.

In the questionnaire, roughly two thirds of the students reported using English for socialising with friends, and 49 social encounters were reported in the on-line diary, representing about a third of the total. These numbers may seem high given that previous research suggests that students have limited opportunities to use English in social situations (see for example, Lewthwaite1996; Spencer-Oatey and Xiong 2006; Morita 2009). However, previous research has mainly been concerned with interactions between international and local students or between international students and other members of the host culture. In our data, about two thirds of the diary encounters were with friends or classmates, and close reading of these entries reveals that 18 out of the 49 social encounters were definitely with other international students while 12 were probably with other students whose first language is not English.

Only one encounter was probably with a native speaker and the rest gave no indication of the first language of their interlocutors. These figures are confirmed by the questionnaire data which shows that only a small proportion of students report having friends locally whose first language is English.

Interview data confirmed that the students were indeed speaking English primarily to other non-native speakers, and that these were mainly classmates from their own course. However, one notable exception was a Chinese student who joined a Bible study group, whose members were mainly non-native speakers and not members of her class. The same student also spent a good deal of her leisure time with a Japanese student and a student from Tajikistan, adding a new dimension to the term 'international student'. What these data show is that the development of social English skills can also be developed through interactions amongst international students themselves, using English as a Lingua Franca (Jenkins 2007, Seidlhofer 2005). This area seems to be rather under-explored in the literature.

Another interesting finding from the interviews was that these students had not yet had the opportunity to meet and socialise with home students. The students accepted that being on a presessional programme meant that such encounters were unlikely but they expressed the hope that this would change once their degree programmes started. However, they also expressed the fear that it might not. As one student said, 
Extract 2

I don't know because I (when in Taiwan) hear that some native students didn't like to stay with non-native ... I heard especially for male

Although 26 students took part in the diary writing activity, only three reported having over five social encounters. This small group seems to be significant as these were also the only three students who reported more than ten encounters in total in their diaries. In other words, it would seem that these students were open to opportunities to use English in whatever situation they found themselves, including social (Murphy-Lejeune 2003; Roberts 2003).

Another point to be made regarding social encounters is that the students reported these as being longer than service encounters, with well over half of the social encounters lasting longer than ten minutes (in comparison to service encounters where only a small number lasted over ten minutes). So while the number of social encounters is smaller, the actual time the students spend speaking English in social situations is probably about the same as in service encounters, indicating that the students may, in fact, have opportunities to practise a range of language skills.

\section{Casual Encounters}

The third type of encounter we have called casual encounters. These are encounters which were not sought out by the students and which took place with complete strangers. An example of this type of encounter would be one which took place in a city train station. The student reported talking to a lady who 'wanted to find a station named London Marylebone and ticket price to there by using Kiosk. I helped her'.

Only a very small number of casual encounters were reported by the students in their diaries, just ten in total, and the majority of these were short, lasting less than five minutes. What is more, half of these casual encounters were reported by one student who seemed to seek them out. In some respects, then, these encounters are of limited significance. However, in terms of developing English language skills, participating in casual encounters clearly represent a learning opportunity, one which this particular student understood. As Roberts (2003:122) states:

While abroad, students can make both conscious and unconscious choices about the extent of their participation and hence the extent of their learning. In one way, participation is learning. 


\section{Academic Encounters}

A fourth type of encounter we have labelled as 'academic'. Although the focus of the study was on English use outside an academic setting, many students reported talking about academic or course-related issues outside the formal setting of their lesson. For example, one student reports on an exchange that took place in the classroom environment but not while a lesson was in progress, where he/she 'talked with friends about 'prepare tomorrow presentation’.

Nine encounters recorded by the students were academic. Two encounters were classified as academic/social as the students reported talking to friends about course-related matters and about general topics in the same encounter. In the questionnaires, when students were asked to rank who they spoke English to the most, almost two thirds put their lecturers (English language teachers) in first position. However, we cannot know where this contact took place and it is likely that a good deal of it at least took place in the classroom as the question did not ask the students to specify where the interaction took place. These encounters would seem to underline the importance of academic experience to these students, which is perhaps not surprising, given the pre-sessional context.

In summary, then, the data revealed that students reported four main areas in which they used English outside the classroom. It is unsurprising that the majority of these are service encounters given that students have only recently arrived in the UK. However, the data show that some students find opportunities for social encounters and casual encounters. The latter were unexpected and we discuss their potential for developing language skills later in the article.

\section{Students' experiences of their encounters}

The previous section examined where the students had opportunities to use English outside the classroom. While such information is useful in indicating the sorts of interactions the students are involved in, it tells us little about how they are experiencing their encounters. To this end, students were asked in their diaries to report both on the type of encounter and to say how they felt about it. It is to the latter we now turn.

Previous research suggests that students' interactions with the host culture especially at the beginning of a period of study abroad can be negative (Brown 2009; Jackson 2008; Morita 2009). However, in our data, about half of the encounters which gave an indication of how the student felt showed entirely positive feelings, while a further quarter or so evidenced 
a mixture of positive and negative reactions. So overall, the student experiences in our study appeared to be mainly positive. In the following example, the student reports favourably on an encounter with a sales assistant to purchase a Bible, describing her feelings by using the adjective 'good'.

\section{Extract 3}

Good. I can understand all the things she said.

The practice of responding to the prompt with an adjective was, as would be expected, common. However, what was of particular interest was that many students provided a description of the encounter, with or without the adjective. These descriptions, which were present in 120 of the 161 encounters, were then analysed in detail in order to better understand the students’ representations of their English interactions.

\section{Participation, socialization and agency}

Sociocultural approaches to analysing international students' participation in their new discourse communities have been widely adopted (see for example, Jackson 2008 and Morita 2004). Such approaches investigate the complex processes students are involved in as they 'negotiate identities, cultures, or power relations' (Morita 2004: 575). Particularly significant in this approach is the concept of agency (Ahearn, 2001; Morita, 2004). At its simplest, Ahearn (ibid:112) defines agency as, 'the socioculturally mediated capacity to act'. Lantolf and Pavlenko (2001:148, cited in Morita 2004:590) develop the socio-cultural aspect of this definition when they state that 'agency is never a "property of a particular individual2' but rather, 'a relationship that is constantly co-constructed and renegotiated with those around the individual and with the society at large'. Examining data for agency, then, involves looking at 'how people attribute responsibility, credit or blame for an event' (Ahearn ibid.:131) but also how other participants in the encounter are accounted for and positioned.

One way to do this is through a linguistic analysis which examines the syntactic choices made by participants in the representation of their experiences. For example, in the following extract, the student was asking a waitress about his/her order. He/she reported difficulties in achieving the goal and took blame upon him/herself:

\section{Extract 4}


I had a bit of confusion when I talked about my orders. I would like to eat a bowl of rice noodle but at that time I didn't know how I should call it.

In this extract, attribution of blame can be seen in that the student places him/herself in subject position (that is, the 'entity' that performs the verb) in the five clauses (see bold). This has the cumulative effect of underlining the role that the student has played as the Actor (Halliday 1975) in the interaction. In contrast, the waitress is entirely absent from the account, as if she had no role in the success or otherwise of the encounter.

A linguistic analysis was carried out on all the diary descriptions in the form of the identification of noun/ pronoun in subject and object position. This analysis showed that agency can be attributed to self (i.e. the student, for example, through the pronoun ' $I$ ') or to 'other' (through nominal and prononominal reference, for example, ' $h e$ helped me'). In other cases, agency was represented as a joint endeavour using pronouns such as we and our in subject position. These different representations of agency are described below.

\section{Students' representations of their English encounters}

Table 1 shows to whom agency is principally attributed in each encounter; whether, overall, agency is attributed only to 'self', whether agency is represented as jointly negotiated or whether agency is attributed to an 'other'.

[Insert Table 1 around here]

The table shows a fairly even distribution between self and joint agency, but other agency is far less reported. This could be because students are concerned with their own role in the success or not of their encounters. However, it may also be a result of the wording of the diary prompt which read: 'How I felt', which may have primed students to focus on themselves (we are grateful to an anonymous reviewer for this observation). Analysis of the data, however, reveals that the first clause in around half of the descriptions begins with a pronoun or noun denoting other or joint agency, for example, 'the staff speak so quick'. This seems to indicate that the prompt may not have had a strong priming effect, leading to a dominant focus on self agency. The following sections discuss each type of representation of agency in more detail.

\section{Self agency}


The analysis showed that in 52 of the 120 descriptions, overall the students positioned themselves as sole agent in the representation, thereby attributing success and failure to self rather than allowing others to take credit or blame. In the following example, the student is reporting on asking about accommodation. He/she feels:

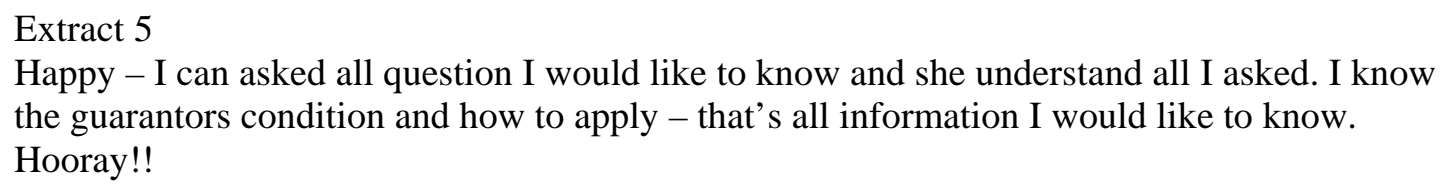

In this encounter, the student's goal was to obtain information about accommodation, which was achieved successfully. By placing him/herself in subject position in most clauses, the student takes most of the credit for the successful outcome. As Dixon (1994:84) argues:

Put very roughly, a speaker will think in terms of doing things to other people to a much greater extent than in terms of things being done to him (sic). In the speaker's view of the world, as it impinges on him and as he describes it in language, he will be the quintessential agent.

The student also states that the accommodation officer 'understand all I asked'. The addition of this clause is salient: firstly, it foregrounds the student's identity as a non-native speaker (such a statement would be redundant were the student a native speaker). Secondly, through the inclusion of the determiner 'all', the student underlines the fact that none of the encounter was problematic. Although the student temporarily shifts agency to the accommodation officer (she understand), he/she soon shifts it back to the self, so that the overall impression is that the student is in control of the encounter (the accommodation officer understands because the student asks clearly). The use of 'she' and 'I' in this extract is in contrast with the use of 'we' in Extract 6 below.

\section{Joint Agency}

In 49 of the 120 descriptions agency was represented as jointly negotiated. A number of these simply underlined the fact that the two participants were successful in communicating. In the following extract the student talked to a cleaner in his/her flat. Unlike the student in Extract 5, this student represents the success of the encounter as being jointly achieved through the use of the pronoun 'we' in the second clause: 
Extract 6

I feel happy because we comprehended

Interestingly, in jointly constructed encounters other than those referring simply to successful communication, students seemed to be more aware of the co-constructed nature of agency when encounters did not proceed successfully than in encounters in which they achieved their goals. The following extract, in which the student reports how he/she felt after asking for a mobile phone top-up, is a case in point:

\section{Extract 7}

A little bit confuse??? Why did she miss typing my phone number for 3 times? In this case I think I told her carefully. Anyway, it's better when she told me showing my phone number on the monitor.

Here, the student's goal is to top up the mobile phone. The student seems to attribute responsibility to the other person for the initial failure of the encounter. There is a contrast here between the action of the 'other' in typing the phone number wrongly and the action of the student who believes he/she spoke clearly. Unlike Miller's (2010) informant who avoided blaming others for his language difficulties, our student clearly attributes blame to the other. It may be that the student is trying to save face (Brown and Levinson 1987) by not admitting to difficulty in pronouncing numbers correctly (a basic English language skill). This analysis seems to be confirmed by the fact that the shop assistant helps the student by showing the number on the monitor, which she would not do if she were deliberately being obstructive throughout the encounter.

The overall effect of this report is that the student expresses frustration and disempowerment as he/she is unable to act to resolve the situation and is reliant on the agency of another, whose action ultimately resolves the situation.

On the other hand, there were also examples of joint agency in successful encounters, as in the following example. This example also shows that Agency is not merely a question of subject positions, however. Students can make us of a range of sophisticated linguistic practices to express agency in the accomplishments of goals as the following extract shows.

Extract 8 
I translate English for the woman at the immigration counter. She is from same country as me and she can't speak and understand English. After helping her, she can pass and finish the interview.

Here the goal is to enable the woman to complete her immigration interview the student was successful in achieving the goal and takes credit for doing so. First of all, the student places him/herself in the role of agent in the process in translating for the woman, who is the recipient of the action. The student then goes on to shift the subject of the verb to the woman herself, firstly to indicate common ground (they are both from the same country), but then to draw attention to a significant difference and thereby to place him/herself in a position of power (the woman cannot speak or understand English, but the student can). Although not explicitly expressed, the subject of the next verb (help) shifts back to the student who is again positioned in the agent role. Finally, agency is transferred to the woman who, thanks to the help of the student, is able to complete her interview successfully.

\section{Other agency}

There are only 19 examples in the data where agency is attributed solely to another. As noted above, this could be because student sojourners will be more focused on their own achievements (or lack of), than on the role of others. In the following example, the student needed to obtain the key to his/her new room and spoke to 'worker'. He/she reported:

Extract 9

They are very friendly to help me open the door, because the worker are on duty

In the case, the student positions the worker(s) in subject position and him/herself as recipient of the action which resulted in the successful outcome of the encounter.

\section{Attenuated Agency}

When goals are not achieved, the data show that inadequate English language skills often play some role. In the next extract, the student needed to fill in a form to pay an accommodation deposit. He/she reported feeling:

Extract 10

A little nervous, because I am not sure the spelling of a word when I fill the form 
Although we do not know whether the student was actually successful in achieving the goal, he/she represents the encounter as problematic and attributes the difficulty to his/her poor English.

Syntactically, the student puts him/herself in subject position, which, we argue above, is often indicative of agency. However, Miller (2010) argues that in situations where an actor is unable to choose a course of action or does not have the capacity to carry out an action, agency is attenuated or weakened. Given that agency is the 'socioculturally mediated capacity to act' (Ahearn 2004: 112) in this case the student cannot be held fully responsible for his or her actions as not knowing the spelling of a word is not a matter of choice.

The distinction between full and attenuated agency can have important implications for students. For this reason, having identified examples in the 120 descriptions that represented different aspects of agency, the diary entries were reanalysed in order to identify representations of attenuated agency, according to Miller's (2010) definition. This categorisation is summarised in the graph below:

[Insert Figure 1around here. Figure 1 - Frequency of attenuated and non-attenuated agency]

As might be expected, attenuated agency was far more prevalent in representations of student agency. It mainly concerned limitations in English ability which reduced the students’ capacity to act. Attenuated agency could also be seen in situations where external circumstances prevented agents from achieving their goals. The following extract gives an example of the other person being unable to act. The student went to the bank because he/she had not received his/her pincode. He/she felt:

\section{Extract 11 \\ Disappointed - The bank officer understand my problems but she can't do anything better because of the bank policy. (Only way I can do is wait, wait and wait the postman send my pincode!!!!!)}

In this extract, the bank officer and the student are placed in subject position as the agents of different actions in the encounter, but they are both represented as not having the capacity to act, therefore neither is attributed with blame for the problem as their agency is attenuated. 


\section{Limitations and Implications}

There are clear limitations to this study. First of all, it was carried out with only a small group of students, the majority of whom shared the same cultural background. Another issue lies in the variation in the number of entries in the diaries, which could mean that the particular experiences of a very small number of students who completed a high number of entries leads to distortion of the data. Moreover, the students who completed the most diary entries are likely to be the ones who are the most highly motivated to seek out opportunities to use English. This was confirmed by the fact that they were also the ones who volunteered to be interviewed and at least one said he wanted to be interviewed because it was a chance to speak English. However, these students also offer insights into what opportunities might exist and where possible interventions could be focused.

In spite of the limitations, there are a number of implications that can be drawn from the data presented. First of all, the complexity of some service encounters in which our international students were engaged from the start of their sojourns in the UK clearly caused problems. This was particularly the case in banks and mobile phone shops. Generally encounters in such places follow particular 'scripts' in that a number of relatively predictable question/answer sequences arise as a result of what the customer wants and/or what the service provider is trying to sell. Students may have been prepared in their English classes for negotiating straight-forward service encounters before they arrive in the UK. However, as we have seen, problems arise when the encounter goes 'off-script', for example, when information the student is not expecting is introduced into the conversation. This can lead to the student not understanding what he/she is being asked, or the service provider not understanding the student.

In the early stages of pre-sessional courses, then, students need to be prepared to cope with service encounters, and what to do when they do not conform to expectations. This could be achieved through specific teaching sessions focusing on both the socio-cultural skills needed (for example, ‘knowing the script’ and, importantly, possible permutations, and 'being firm but polite') and language skills (for example, asking for clarification if something is not understood, and paraphrasing). Students could also be encouraged to report their encounters in the class so that the students learn from each other and develop strategies for coping in these service contexts.

The second implication concerns the opportunities that interaction amongst international students themselves offers for developing social language skills. As already 
mentioned, this is an under-researched area, but its potential should not be underestimated. In our study there was some evidence that students themselves are beginning to realise the value of such interaction as one student reported in the interview:

\author{
Extract 12 \\ you know I want to make friends with different people in different country yeah because if I \\ made friends with other countries people I can practise English and also is a good chance to \\ know the culture of the other country
}

Social programmes are an integral part of pre-sessional courses, but course directors may wish to consider activities in which interaction between international students can be cultivated more explicitly with the express aim of building confidence and improving language skills (Morita 2009: 457) also recommends that international students should be encouraged to interact with 'their peers in informal social gatherings'). When such interaction was engineered on social programme following the outcome of the study reported here, reactions were extremely positive with students reporting both an increased confidence in social language use and a developing empathy with 'real' British culture.

The third implication is that students need to be encouraged to seek out casual encounters as they represent an important learning opportunity. This might appear challenging for university staff; however, following Roberts (2003), we would suggest that students need to be shown how to participate more extensively, by, for example, joining special interest groups. Although further research is necessary to identify the factors that may contribute to some students being naturally more successful at seeking out casual encounters, raising awareness of how students can develop such contacts would undoubtedly be helpful. One approach on pre-sessional courses may be to encourage language students to become ‘ethnographers’ (Roberts et al. 2001) for example, by 'hanging around in a bar’ (ibid). Students could be asked to go to a bar (pub, coffee shop) to observe patterns of organisation and socialisation. Such observations of behaviour would help students to understand the social activities that British people engage in and also give students more confidence in participating in these activities themselves.

The final implication concerns the phenomenon of attenuated agency. Students in our data frequently reported that they did not achieve goals, or struggled to achieve them, because of poor English skills, which led to a lack of control over their encounters. The dialogic nature of agency means that responsibility for successful outcomes does not lie wholly with 
one interlocutor: speakers can be supportive, combative and even obstructive, amongst other things. Students therefore need to be taught how to obtain the cooperation of the other in order to improve their chances of achieving their goals, through, for example, asking for help. Some students already reported using strategies to overcome attenuated agency, as in the following example where the student was talking to an accommodation office about changing his/her room:

\section{Extract 13}

So-so. Sometime I cannot catch their words and ask them to repeat what they saying. However, at last I understand them.

In this way, the attenuated agent has the opportunity to become an active agent, with a capacity to act (Ahearn, 2004).

An example where the use of a strategy could have helped a student is Extract 10, in which the student struggles to spell a word. An obvious strategy would be to ask the accommodation officer for the correct spelling. However, the fact that the student does not appear to have done this indicates that it may not be just a matter of teaching linguistic strategies (How do you spell X?). Unless the student has the confidence to use such strategies and realises that asking for a spelling is culturally and socially acceptable, he/she may feel that to do so potentially involves a loss of face and remain unable to act. Pre-sessional programmes therefore need to consider not only how they can equip students with linguistic strategies to compensate for limited language skills but, perhaps even more importantly, they need to develop students' cultural awareness so that they are not inhibited by these limitations but rather empowered to act when it is their best interests to do so.

\section{Conclusion}

Pre-sessional students have generally been under-represented in the literature on study abroad as have the English language experiences of bilingual international students outside the classroom.

This study has addressed these issues to some extent by investigating the opportunities a group of pre-sessional students had to use English. The students in this study did not report dissatisfaction with their social situation in the same way as the students in, for example, Brown (2009), Lewthwaite (1996), Morita (2009) and Perrucci and Hu (1995). This may be due to the fact that, as their course took place in the summer and the British students 
were not present, the pre-sessional students' expectations were different as far as social encounters were concerned. However, the students in our study did face considerable challenges and often found themselves participating in complex interactions with limited English ability. The study shows that when international students first arrive in the UK, they must meet a number of challenges outside the immediate university context in order to live successfully in their new country.

The study also investigated how students represented their experiences, and showed agency to be a key concept in understanding students' perceptions of their role in the success or otherwise of their encounters. Students often displayed attenuated agency, attributing blame for their difficulties to their English skills.

The findings of the study imply that it should be possible to address linguistic issues and develop socio-cultural competence in order to support students in taking a more active role in their interactions. In fact, it may take very little to make an enormous difference to an international student's perception of their competence and ability to act. As one student reported on shopping in the supermarket:

ask how much, and give the money, then be polite to say thank you. I felt that I do live in the UK now.

\section{References}

Ahearn, L. M. (2001). "Language and agency." Annual Review of Anthropology, 30, 109-137. Brown, L. (2009). "A failure of communication on the cross-cultural campus." Journal of Studies in International Education, 13, 439-454.

Brown, P., and Levinson, S. (1987). Politeness: Some universals in language use, Cambridge: Cambridge University Press.

Burns, R. B. (1991). "Study and stress among first year overseas students in an Australian university." Higher Education Research and Development, 10(1), 61-77.

Chang, C.E., and Strauss, P. (2010)." 'Active agents of change?' Mandarin-speaking students in New Zealand and the thesis writing process". Language and Education,24 (5), 415 $-429$

Chushner, K., and Karim, A. U. (2004). "Study abroad at the university level", in D. Landis, J. M. Bennett, and M. J. Bennett, (eds.), Handbook of Intercultural Training 3rd edition.Thousand Oaks, CA: Sage.

Dixon, R. M. W. (1994). Ergativity, New York: Cambridge University Press. 
DuFon, M. A., and Churchill, E. (2006). Learning to take leave in social conversations: a diary study, Clevedon: Multilingual Matters.

Halliday, M.A.K. (1985). An Introduction to Functional Grammar $1^{\text {st }}$ edition. London:Arnold.

Hassell, T. (2006). "Learning to take leave in social conversations: a diary study", in M. A. DuFon and E. Churchill, (eds.), Language Learners in Study Abroad Contexts. Clevedon: Multilingual Matters, pp. 31-58.

Jackson, J. (2008). Language, Identity and Study Abroad, London: Equinox.

Jenkins J. (2007). English as a Lingua Franca: Attitude and Identity. Oxford: Oxford University Press.

Lantolf, J. P., \& Pavlenko, A. (2001). “(S)econd (L)anguage (A)ctivity: Understanding learners as people”, in M. Breen.(Ed.), Learner contributions to language learning: New directions in research (pp. 141-158). London: Pearson.

Lewthwaite, M. (1996). "Study of international students’ perspectives on cross-cultural adaptation." International Journal for the Advancement of Counselling, 19, 167-185.

Lecki, I. (1992). Understanding ESL Writers.Portsmouth, NH: Boynton/Cook

Miles, M. B., and Huberman, A. M. (1994). Qualitative Data Analysis. (2nd edition), London: Sage.

Miller, E. R."Indeterminacy and interview research: Co-constructing ambiguity and clarity in interviews with an adult immigrant learner of English. Applied Linguistics Advance Access published October 8 2010, doi:10.1093/applin/anq039.

Mori, S. (2000). "Addressing the mental health concerns of international students." Journal of Counseling and Development, 78(137-144).

Moritia, N. 2004. "Negotiating Participation and Identity in Second Language Academic Communities". TESOL Quarterly, 38(4), 573-603

Morita, N. (2009) "Language, culture, gender, and academic socialisation". Language and Education, 23 (5), 443 - 460.

Murphy-Lejeune, E. (2003). "An experience of interculturality:student travellers abroad", in G. Alred, M. Byram, and M. Fleming, (eds.), Intercultural Experience and Education. Clevedon: Multilingual Matters, pp. 101- 113.

Perrucci, R., and Hu, H. (1995). "Satisfaction with social and educational experiences among international graduate students." Research in Higher Education, 36(4), 491-508.

Richards, K. (2003). Qualitative Inquiry in TESOL, Hampshire: Palgrave Macmillan. 
Roberts, C. (2003). "Ethnography and cultural practice:ways of learning during residence abroad", in G. Alred, M. Byram, and M. Fleming, (eds.), Intercultural Experience and Education. Clevedon: Multilingual Matters, pp. 114-130.

Roberts, C., Bryam, M., Barro, A., Jordan, S., and Street, B. (2001). Language Learners as Ethnographers, Clevedon: Multilingual Matters.

Segalowitz, N., Freed, B., Colletine, J., Lafford, B., Lazar, N., and Diaz-Campos, M. (2004). "A comparison of Spanish second language acquisition in two different learning contexts: study abroad and the domestic classroom." Frontiers: The Interdisciplinary Journal of Study Abroad, 10(1-18).

Seidlhofer B. (2005). "English as a lingua franca". ELT Journal 59(4), 339-341.

Spencer-Oatey, H., and Xiong, Z. (2006). "Chinese students’ psychological and sociocultural adjustments to Britain: an empirical study." Language Culture and Curriculum, 19(1), $37-53$.

Volet, S. E., and Ang, G. (1998). "Culturally mixed groups on international campuses: an opportunity for inter-cultural learning." Higher Education Research and Development, 17(1), 5-23.

Wan, T. Y., Chapman, D. W., and Biggs, D. A. (1992). "Academic stress of international students attending US universities." Research in Higher Education, 33(5), 607-623.

Ward, C., Bochner, S., and Farnham, A. (2001). The Psychology of Culture Shock, Hove: Routledge.

Xu, M. (1991). "The impact of English-language proficiency on international students' perceived academic difficulty." Research in Higher Education, 32(5), 557-570.

Yeh, C. J., and Inose, M. (2003). "International students’ reported English fluency, social support satisfaction, and social connectedness as predicators of acculturative stress." Counselling Psychology Quarterly, 16(1), 15-28. 
1 All extracts faithfully represent the students' own words. 